\section{BEDRIJFSECONOMISCHE OPSTELLEN AANGEBODEN AAN PROF. LIMPERG}

Bij de bespreking van bovengenoemd werk in het Octobernummer is zeer tot het leedwezen van ondergeteekende geen gewag gemaakt van de bijdrage van den heer $E$. J. Flipse over "Kostenvergelijkingen in den detailhandel". Ik zou dit verzuim thans willen herstellen door alsnog op deze studie uitdrukkelijk de aandacht te vestigen. Het is immers zoo, dat kostenvergelijkingen momenteel snel en over een veel grooter gebied dan den detailhandel in zwang komen. Terwijl de heer Flipse meer speciaal de bedrijfseconomische gebruiksmogelijkheden naar voren brengt, worden bedrijlsvergelijkingen en daarop steunende calculatieschema's nu in toenemende mate gebezigd voor bedrijfs- en prijscontrōle van overheidswege, dus voor een uitgesproken economisch politiek doel.

Juist de snelle verbreiding van kostenvergelijkingen onder de huidige abnormale omstandigheden makt het wenschelijk acht te slaan op zekere onnauwkeurigheden en andere bezwaren, welke deze methode aankleven. $Z_{i j}$ heeft daardoor als normgevend criterium bij de beoordeeling van individueele bedrijfsprestaties een minder volstrekte waarde dan velen geneigd zijn aan te nemen. De verdienste van den heer Flipse is, dat hij zoowel op mogelijkheden wijst, wrelke bij voorzichtige kanteering bereikbaar zijn, als op het gevaar van het trekken van onwetenschappelijke conclusies ten deze. Zoodoende is zijn bijdrage stimuleerend tot verder bedrijfseconomisch onderzoek, dat zich naar mijn meening vooral zal moeten toespitsen op de analyse en de interpretatie van bij bedrijfs- en kostenvergelijkingen aan het licht tredende afwijkingen. Wanneer hierin vorderingen worden gemaakt zal men vanzelf op de grenzen stuiten, welke de toepassing van dit moderne studie- en contrōlemiddel limiteeren en welke ten deele niet kunnen worden overwonnen.

\section{P. P. VAN BERKUIM}

\section{TOE- EN AFNEMENDE MEEROPBRENGSTEN}

\section{(Antwoord aan den Heer Roetink.)}

Het naschrift van den Heer Roetink naar aanleiding van mijn artikel, getiteld ,Eenige beschouwingen over de wetten van toe- en afnemende meeropbrengsten" in het M.A.B. van Februari en Maart 1940, bestaat uit drie deelen en wel de volgende:

I. Een verweer van den Heer Roetink als zou hij uit zijn wiskundige afleidingen de wet van de afnemende meeropbrengst niet ",bewezen" hebben geacht.

Il. Een verdediging van zijn definitie van de wet van de toenemende meeropbrengst $\left(\frac{\Delta r_{n}}{\Delta K_{n}}>\frac{\Delta r_{n}+1}{\Delta K_{n}+1}\right)$ en een afwijzing van mijn definitie van dezelfde wet $\left(\frac{\triangle \mathrm{P}}{\mathrm{P}}<\frac{\Delta \mathrm{K}}{\mathrm{K}}\right.$ of $\mathrm{E}<1$ zie pag. 29, 1e kolom boven M.A.B. Febr. 1940).

III. Een serie insinuaties en verwarring stichtende vaagheden ten aanzien van mijn logica, fantasie, "gezag" op het gebied der wiskunde enz.
Ik zal deze punten achtereenvolgens bespreken al zal de lezer mij ten goede houden, dat $\mathrm{ik}$ het derde punt slechts summier zal behandelen.

Komen wij tot het eerste punt. In het M.A.B. Nov. 1939 pag. 178, le kolom e.v. vinden wij een serie ongelijkheden door den Heer Roetink in wiskundige symbolen voorgesteld. Vrijwel onmiddellijk hierop volgt dan gecursiveerd:

„Thans is het dus duidelijk geworden, dat toenmende, ge,lijkblijvende en afnemende productiviteit niet gelijkwaardige „uitdrukkingen zijn met resp. toenemende, gelijkblijvende en ,afnemende meeropbrengsten;

.,dat deze uitdrukkingen in de literatuur onvoldoend exact ,worden gebruikt;

,dat alleen de wet van de afnemende meeropbrengsten geldt;

,dat deze wet steeds geldt voor elk productiemiddel;

dat hierbij toenemende productiviteit zeer wel mogelijk is, en bij aanvankelijk voldoend kleine toevoegingen stellig zal optreden:

"dat men met evenveel recht kan spreken van „wet der "toenemende minderopbrengsten":

, dat een zgn. ,wet der toenemende meeropbrengsten" niet geldt".

Hieruit heb ik geconcludeerd dat de Heer Roetink de wet van de alnemende meeropbrengst uit zijn wiskundige beschouwingen bewezen acht. Als hij zegt ,Thans is het dui,delijk geworden (onderstreept door S.K.) dat deze uitdruk".kingen in de literatuur onvoldoende exact worden gebruikt", dan kan dit alleen uit zijn voorafgaande beschouwingen zijn afgeleid. En als dan onmiddellijk hieronder volgt

"dat alleen de wet van de afnemende meeropbrengsten ".geldt enz,"

dan kan dit alleen op dezelfde manier worden verstaan.

Als de Heer Roetink nu achteraf (M.A.B. Maart 1940. pag. 51, le kolom boven) zegt .,Wat in de daarop volgende ,alinea staat in cursieve letter is een samenvatting van het ,gehele artikel. Alle gemaakte onderstellingen zijn vooraf uit"drukkelijk vermeld - mij valt in dezen niets te verwijten" dan moet ik verklaren, dat de bedoeling bij herhaalde lezing en na de toelichting van den Heer Roetink nog niet duidelijk wordt. Als de Heer Roetink in de gememoreerde alinea's bedoeld heeft zijn praemissen en conclusies gelijkelijk af te drukken dan had hij op deze plaats duidelijk moeten laten zien wat praemisse en wat conclusie is, afgezien van het feit dat het dooreenmengen van praemissen en conclusies altijd fout is. Het is dan ook niet waar dat "Thans" is duidelijk geworden dat de wet van de afnemende meeropbrengst altijd geldt, zooals de Heer Roetink blijkens bovenstaand citaat uitdrukkelijk schrijft.

Wat wel waar is, is, dat van den aanvang of (dit is iets anders dan thans) vast staat dat wij op niet-wiskundige gronden moeten uitgaan van de wet van de afnemende meeropbrengst.

Interpreteeren wij dit alles nu eens op de voor den Heer Roetink meest gunstige wijze. De Heer Roetink schrijft slordig en duister (de lezer kan dit zelf controleeren) en heeft dit punt inderdaad beter bedoeld dan hij het heeft opgeschreven. Dit kan tenslotte een ieder gebeuren en als de Heer Roetink mij zou hebben verzekerd, dat de zaak zoo in elkaar zat, zou ik het graag hebben geloofd en zijn overgegaan tot de orde van den dag. Maar nu vraag ik: waarom maakt de Heer Roetink zich toch zoo druk? Waarom gebruikt hij zulke groote woorden en werkt hij met kopjes, die aan oorlogs- 
bulletins doen denken? Zoo voert men toch geen wetenschap pelijk debat. Ik neig dan ook sterk tot de conclusie: „qui se fâche a tort".

Het tweede verschilpunt loopt over de definitie van het begrip afnemende meeropbrengst.

I $k$ heb dat gedefinieerd als het geval waarin

$$
\begin{aligned}
& \frac{\Delta \mathrm{P}}{\mathrm{P}}<\frac{\Delta \mathrm{K}}{\mathrm{K}} \text { of } \\
& \mathrm{K} \Delta \mathrm{P}<1 . \\
& \mathrm{P} \quad \Delta \mathrm{K}<1 .
\end{aligned}
$$

waarbij dan $\frac{K}{P} \frac{\Delta P}{\Delta K}$ (voorgesteld door $E$ ) een elasticiteitscoëfficient werd genoemd. De Heer Roetink stelt hiertegenover zijn definitie $\Delta \mathrm{r}_{n}>\frac{\Delta \mathrm{r}_{n}+1}{\Delta \mathrm{K}_{n}+1}$ (M.A.B. Maart 1940 pag. 51, 2e kolom) en schijnt dit als iets nieuws te beschouwen. Hij schrijft tenminste t.a.p.:

, $\mathrm{Na}$ het verschijnen van mijn artikel werd ik van ,,méér dan één zijde opmerkzaam gemaakt op het proef,schrift van Dr O. Bakker ,De wetten der toe- en af"nemende meeropbrengsten". De hierin voorkomende ,,wiskunde is in volkomen overeenstemming met die ,.welke ik heb uiteengezet en aan mijn beschouwingen ", heb ten grondslag gelegd."

Ziehier dus: een beroep op literatuur, die de schrijver na de publicatie van zijn artikel heeft in handen gekregen met de uitdrukkelijke mededeeling van de volgorde: dit is dus de pretentie van originaliteit. Tot mijn spijt moet ik den Heer Roetink - hoezeer ik zijn goede trouw hier waarlijk niet in twijfel trek - de illusie ontnemen, dat hij hier iets nieuws heeft gebracht. Integendeel heeft hij klaarblijkelijk door onbekendheid met de materie een oude controverse opgerakeld, waarvan ik meende dat zij allang als afgedaan kon worden beschouwd. In artikelen in het Economic Journal" van de jaren 1897 en 1911 wordt de definitie van de wet der diminishing returns door niemand minder dan Edgeworth zeer grondig en critisch behandeld. ${ }^{1}$ )

Edgeworth geeft de volgende definitie:

,In other words the law of increasing cost or dimi.nishing returns holds good when the ratio of the last ,increment of cost to the last increment of produce is .,greater than the ratio of the penultimate (voorlaatste, ,S. K.) increment of cost to the penultimate increment ,of produce."

Dit is in woorden dezelfde definitie als die de Heer Roetink geeft en waarvan ik dus op nader te ontwikkelen gronden afwijk.

Ik moet nu opmerken, dat de Heer Roetink op de zaak bij lange na niet zoo diep ingaat als dit tientallen jaren geleden door Edgeworth is gedaan. $\mathrm{H}_{\mathrm{ij}}$ verwijt mij op pag. 51, $2^{\circ}$ kolom M.A.B. Maart 1940 voor de definitie van de ,diminishing returns" uit de gaan van de betrekking

\footnotetext{
1) Voor den lezer die zich voor het onderwerp meer in het bijzonder interesseert, merken wij op dat de artikelen zijn afgedrukt in „Papers relating to Political Economy by F. Y. Edgeworth, Volume I.

Macmillan London 1925".
}

$\frac{\triangle \mathrm{P}}{\mathrm{P}}<\frac{\triangle \mathrm{K}}{\mathrm{K}}$ en zegt dan dat deze definitie niet strijdig is met een betrekking $\frac{\Delta r_{n}}{\Delta K_{n}}<\frac{\Delta r_{n}+1}{\Delta K_{n}+1}$ welke laatste formuleering betrekking heeft op toenemende meeropbrengsten. Als toelichting vinden wij hiervoor eigenlijk niet meer dan de woorden: „Bewijs voor den lezer". Verder bewijst het zinnetje: ,Deze consequentie is blijkbaar bij velen onbekend" nog duidelijk dat de Heer Roetink de literatuur over het onderwerp niet kent. Zooals wij reeds opmerkten, nog nader zullen uitwerken is de zaak al meer dan 40 jaar geleden aan de orde geweest.

Mij dunkt, dat de Heer Roetink hier wel bijzonder te kort schiet. Hier had bewijs noch toelichting noch nadere analyse aan den lezer mogen worden overgelaten omdat dit nu juist het punt is waar het op aankomt. De Heer Roetink had min der onzakelijke groote woorden moeten gebruiken en hier bewijs en analyse moeten geven. Hiermede zou hij de basis voor een verder vruchtbaar debat hebben gelegd.

Intusschen wil ik van de zonderlinge methode van mijn opponent geen gebruik maken om het debat hier af te breken. Maar dan is het ook noodig, dat ik doe, hetgeen de Heer Roetink had moeten doen, dat is het bewijs en de analyse van zijn stelling leveren. Pas hierna zal het mogelijk zijn dat ik van mijn afwijkend standpunt gemotiveerd doe blijken.

Ik geef dus als definitie van de wet van de afnemende meeropbrengst

$$
\frac{\Delta \mathrm{P}}{\mathrm{P}}<\frac{\Delta \mathrm{K}}{\mathrm{K}} \text { of } \mathrm{E}=\frac{\mathrm{K}}{\mathrm{P}} \frac{\Delta \mathrm{P}}{\Delta \mathrm{K}}<1
$$

Men kan natuurlijk E ook schrijven als $\frac{K}{P}: \frac{\Delta K}{\Delta P}$

Stellen wij eens dat tusschen $\mathrm{K}$ en $\mathrm{P}$ de volgende betrekking bestaat

$$
\mathrm{K}=\frac{1}{2} \mathrm{P}^{2}+\mathrm{P}+5
$$

Is dan b.v. $\mathrm{P}=10$ dan is $\mathrm{K}=\frac{1}{2} \cdot 10^{2}+10+5=65$. Is $\mathrm{P}=\mathrm{O}$ dan is $\mathrm{K}=5$. Wij merken reeds nu op dat het getal 5 iets voorstelt dat men in de Engelsche literatuur gewend is ,overhead costs" te noemen. Het zijn de kosten, die men in ieder geval, ook als er niets wordt geproduceerd, heeft te dragen.

De vraag, die wij nu stellen, is: hoe kan men $\frac{\Delta K}{\triangle P}$ berekenen? Laten wij P eens met $\frac{1}{1000} \mathrm{P}$ toenemen m.a.w. stellen wij $\triangle \mathrm{P}=\frac{1}{1000} \mathrm{P}$. Wij krijgen dan

$$
\begin{aligned}
& \mathrm{K}+\Delta \mathrm{K}=\frac{1}{2}\left(\mathrm{P}+\frac{1}{1000} \mathrm{P}\right)^{2}+\mathrm{P}+\frac{1}{1000} \mathrm{P}+5 \ldots \ldots(3) \\
& \text { En omdat volgens }(2) \mathrm{K}=1 / 2 \mathrm{P}^{2}+\mathrm{P}+5 \text { is } \\
& \begin{array}{r}
\Delta \mathrm{K}=\frac{1}{2}\left(\mathrm{P}^{2}+\frac{2}{1000} \mathrm{P}^{2}+\frac{1}{1000000} \mathrm{P}^{2}\right)+ \\
+\mathrm{P}+\frac{1}{1000} \mathrm{P}+5-\frac{1}{2} \mathrm{P}^{2}-\mathrm{P}-5
\end{array}
\end{aligned}
$$


$\Delta \mathrm{K}=\frac{\mathrm{i}}{2} \mathrm{P}^{2}+\frac{1}{1000} \mathrm{P}^{2}+\frac{1}{2000000} \mathrm{P}^{2}+$

$$
+\mathrm{P}+\frac{1}{1000} \mathrm{P}+5-\frac{1}{2} \mathrm{P}^{2}-\mathrm{P}-5
$$

$\Delta \mathrm{K}=\frac{1}{1000} \mathrm{P}^{2}+\frac{1}{2000000} \mathrm{P}^{2}+\frac{1}{1000} \mathrm{P}$

Omdat wij stelden $\triangle \mathrm{P}=\frac{1}{1000} \mathrm{P}$ is $\mathrm{nu}$

$\frac{\Delta \mathrm{K}}{\Delta \mathrm{P}}=\frac{\Delta \mathrm{K}}{\frac{1}{1000} \mathrm{P}}=\mathrm{P}+\frac{1}{2000} \mathrm{P}+\mathrm{l} . . .$.

Wij zien duidelijk dat als $\triangle P$ steeds kleiner wordt, dit eveneens het geval is met $\frac{1}{2000} \mathrm{P}$ rechts van het $=$ teeken en als $\triangle P$ dus zeer dicht tot 0 nadert, mogen wij $\frac{1}{2000} P$ verwaarloozen. Voor dit geval schrijven wij $\frac{\Delta K}{\Delta P}$ de uitdrukking dK $\frac{\mathrm{dK}}{\mathrm{dP}}$ en krijgen

$$
\frac{\mathrm{dK}}{\mathrm{dP}}=\mathrm{P}+1 . \cdot . \cdot . \cdot .
$$

Wij merken op, dat wij den lezer hier op populaire wijze een differentiaal quotient hebben doen berekenen. ${ }^{2}$ ) $\mathrm{Wij}$ kunnen nu de elasticiteitscoëfficient voor iedere willekeurige productie berekenen. Is b.v. $\mathrm{P}=10$ dan is $\mathrm{K}$ zooals wij hierboven hebben gezien 65. Dan is $\frac{K}{\mathrm{P}}=6 \frac{1}{2}$. $\frac{\mathrm{dK}}{\mathrm{dP}}$ vinden wij door in de vergelijking (5) $\mathrm{P}=-10$ te stellen: $\frac{\mathrm{dK}}{\mathrm{dP}}=$ $10+1=11$. Dan is

$$
E=\frac{K}{P}: \frac{d K}{d P}=\frac{6 \frac{1}{2}}{11}=\frac{13}{22}
$$

De lezer is nu gemakkelijk in staat om de onderstaande tabel na te rekenen.

2) Voor sommige lezers wellicht iets lastiger, maar strenger is de volgende afleiding.

Laat $P$ veranderen met $\triangle P$. Wij krijgen dan

$$
\begin{aligned}
& K+\Delta K=\frac{1}{2}\left[P^{2}+2 P \triangle P+(\Delta P)^{2}\right]+P+\Delta P+5 \\
& \Delta \mathrm{K}=\frac{1}{2} \mathrm{P}^{2}+\mathrm{P} \Delta \mathrm{P}+\frac{(\triangle \mathrm{P})^{2}}{2}+\mathrm{P}+\Delta \mathrm{P}+5-\mathrm{K}= \\
& =\frac{1}{2} \mathrm{P}^{2}+\mathrm{P} \triangle \mathrm{P}+\frac{(\triangle \mathrm{P})^{2}}{2}+\mathrm{P}+\triangle \mathrm{P}+5-\frac{1}{2} \mathrm{P}^{2}-\mathrm{P}-5= \\
& =\mathrm{P} \Delta \mathrm{P}+\frac{(\triangle \mathrm{P})^{2}}{2}+\Delta \mathrm{P} \\
& \frac{\triangle \mathrm{K}}{\Delta \mathrm{P}}=\mathrm{P}+\frac{1}{2} \Delta \mathrm{P}+1
\end{aligned}
$$

\begin{tabular}{|c|c|c|c|c|c|}
\hline $\mathrm{p}$ & $\mathrm{K}$ & $\begin{array}{l}\mathrm{K} \\
\mathrm{P}\end{array}$ & $\frac{d K}{d P}$ & $E=\frac{K}{P} ; \frac{d K}{d P}$ & $\begin{array}{l}\text { Vergelijking } \\
\text { der meer- } \\
\text { opbrengsten }\end{array}$ \\
\hline (1) & (2) & (3) & (4) & (5) & (6) \\
\hline 1 & $6 \frac{1}{2}$ & $6 \frac{1}{2}$ & 2 & $3 \frac{1}{4}=3.25$ & \\
\hline 2 & 9 & $4 \frac{1}{2}$ & 3 & $1 \frac{1}{2}=1.5$ & $\frac{1}{2 \frac{1}{2}}$ \\
\hline 3 & $12 \frac{1}{2}$ & $4 \frac{1}{6}$ & 4 & $1 \frac{1}{24}=1.04$ & $\frac{1}{3 \frac{1}{2}}$ \\
\hline 4 & 17 & $4 \frac{1}{4}$ & 5 & $\frac{17}{20}=0.85$ & $\frac{1}{4 \frac{1}{2}}$ \\
\hline 5 & $22 \frac{1}{2}$ & $4 \frac{1}{2}$ & 6 & $\frac{3}{4}=0.75$ & $\frac{1}{5 \frac{1}{2}}$ \\
\hline 6 & 29 & $4 \frac{5}{6}$ & 7 & $\frac{29}{42}=0.69$ & $\frac{1}{6 \frac{1}{2}}$ \\
\hline 7 & $36 \frac{1}{2}$ & $5 \frac{3}{14}$ & 8 & $\begin{array}{c}73 \\
112\end{array}=065$ & $\frac{1}{7 \frac{1}{2}}$ \\
\hline 8 & 45 & $5 \frac{5}{8}$ & 9 & $\frac{45}{72}=0.63$ & $\frac{1}{8 \frac{1}{2}}$ \\
\hline 9 & $54 \frac{1}{2}$ & $6 \frac{1}{18}$ & 10 & $\frac{109}{180}=0.61$ & $\frac{1}{9 \frac{1}{2}}$ \\
\hline 10 & 65 & $6 \frac{1}{2}$ & 11 & $\frac{13}{22}=059$ & $\frac{1}{10 \frac{1}{2}}$ \\
\hline
\end{tabular}

Laat men nu $\triangle \mathrm{P}$ steeds dichter tot 0 naderen, dan wordt de bijdrage van $1 / 2 \triangle P$ in het rechterlid van (a) steeds onbelangrijker, om ten slotte in het grensgeval $\triangle P=0$ geheel te verdwijnen. Men heeft de gewoonte om in dit grensgeval $\frac{\mathrm{dK}}{\mathrm{dP}}$ te schrijven in plaats van $\frac{\Delta \mathrm{K}}{\Delta \mathrm{P}}$. Dus:

$$
\frac{\mathrm{dK}}{\mathrm{dP}}=\mathrm{P}+1 \text {. }
$$

TABEL I

Als wij uitgaan van de definitie van den Heer Roetink dan vergelijken wij $\frac{\Delta r_{n}}{\Delta K_{n}}$ en $\frac{\Delta r_{n+1}}{\Delta K_{n+1}}$; in onze notatie $\frac{\Delta P_{n}}{\Delta K_{n}}$ en $\triangle \mathrm{P}_{n+1}$ Passen wij deze formules toe op de getallen uit onze tabel, dan zien wij het volgende:

Gaat $P$ over van 1 naar 2 dan is $\frac{\Delta P_{n}}{\Delta K_{n}}=\frac{1}{2 \frac{1}{2}}\left(\Delta K=9-6 \frac{1}{2}\right)$.

Gaat $\mathrm{P}$ over van 2 naar 3 dan is

$$
\frac{\Delta \mathrm{P}_{\mathrm{n}}}{\Delta \mathrm{K}_{\mathrm{n}}}=\frac{1}{3 \frac{1}{2}}\left(\Delta \mathrm{K}_{*+1}=12 \frac{1}{2}-9\right) \text {. }
$$

Dit vinden wij in kolom (6) van de tabel.

Kolom (6) geeft de definitie van afnemende meeropbrengst volgens den Heer Roetink. Inderdaad wordt de reeks $\frac{1}{2 \frac{1}{2}}, \frac{1}{3 \frac{1}{2}}$, enz, steeds kleiner: wij vinden hier dus afnemende meerop- 
brengsten. Kolom (5) geeft mijn definitie: er is afnemende meeropbrengst als $\mathrm{E}=\frac{\mathrm{K}}{\mathrm{P}}=\frac{\mathrm{dK}}{\mathrm{dP}}<1$. Wij zien echter dat voor de waarden van $\mathrm{P}=1, \mathrm{P}=2$ en $\mathrm{P}=3$ voor $\mathrm{E}$ gevonden wordt resp. $3.25,1.5$ en 1.04 dus toenemende meeropbrengsten. Dit is wat de Heer Roetink bedoelt als hij zegt dat mijn definitie van afnemende meeropbrengst ook nog toenemende meeropbrengst toelaat.

Dit is de toelichting, die de Heer Roetink zeer ten onrechte achterwege heeft gelaten des te meer ten onrechte omdat de Heer Roetink zich hierdoor onttrokken heeft aan de plicht van verdere analyse, welke analyse resultaten oplevert die zich tegen hem keeren en wel op de volgende gronden:

Wij hebben gezien, dat in den vorm $\mathrm{K}=\frac{1}{2} \mathrm{P} 2+\mathrm{P}+5$ het getal 5 de overhead costs voorstelt. Dit is een kostencomplex, dat met de vragen van de onvolkomen verbindingen, waar het bij de wet van de afnemende meeropbrengst om gaat, volstrekt niets te maken heeft. Wij onderzoeken wanneer wij over de opbrengstwetten spreken immers de resultaten van zeer kleine toevoegingen van willekeurig deelbare kostenele-

TABEL II

\begin{tabular}{|c|c|c|c|c|c|}
\hline $\mathrm{P}$ & K & $\begin{array}{l}\mathrm{K} \\
\mathrm{P}\end{array}$ & $\frac{d K}{d P}$ & $\mathrm{E}=\frac{\mathrm{K}}{\mathrm{P}}: \frac{\mathrm{dK}}{\mathrm{dP}}$ & $\begin{array}{l}\text { Vergeiijking } \\
\text { der meer- } \\
\text { opbrengsten }\end{array}$ \\
\hline (1) & (2) & (3) & (4) & (5) & (6) \\
\hline 1 & $1 \frac{1}{2}$ & $1 \frac{1}{2}$ & 2 & $\frac{3}{4}=0.750$ & \\
\hline 2 & 4 & 2 & 3 & $\frac{2}{3}=0.667$ & $\frac{1}{2 \frac{1}{2}}$ \\
\hline 3 & $7 \frac{1}{2}$ & $2 \frac{1}{2}$ & 4 & $\frac{5}{8}=0.625$ & $\frac{1}{3 \frac{1}{2}}$ \\
\hline 4 & 12 & 3 & 5 & $\frac{3}{5}=0.600$ & $\frac{1}{4 \frac{1}{2}}$ \\
\hline 5 & $17 \frac{1}{2}$ & $3 \frac{1}{2}$ & 6 & $\frac{7}{12}=0583$ & $\frac{1}{5 \frac{1}{2}}$ \\
\hline 6 & 24 & 4 & 7 & $\frac{4}{7}=0571$ & $\frac{1}{6 \frac{1}{2}}$ \\
\hline 7 & $31 \frac{1}{2}$ & $4 \frac{1}{2}$ & 8 & $\frac{9}{16}=0.563$ & $\frac{1}{7 \frac{1}{2}}$ \\
\hline 8 & 40 & 5 & 9 & $\frac{5}{9}=0556$ & $\frac{1}{8 \frac{1}{2}}$ \\
\hline 9 & $49 \frac{1}{2}$ & $5 \frac{1}{2}$ & 10 & $\frac{11}{20}=0550$ & $\frac{1}{9 \frac{1}{2}}$ \\
\hline 10 & 60 & 6 & 11 & $\frac{6}{11}=0545$ & $\frac{1}{10 !}$ \\
\hline
\end{tabular}

menten; d.i. het tegenovergestelde van overhead costs om deze overhead costs te elimineeren stellen wij deze in (2) gelijk 0. Onze functie wordt dan $\mathrm{K}=\frac{1}{2} \mathrm{P}_{2}+\mathrm{P}$.

Gemakkelijk valt in te zien, dat in dit geval $\frac{d K}{d P}$ door dezelfde vergelijking $\frac{\mathrm{dK}}{\mathrm{dP}}=\mathrm{P}+1$ wordt voorgesteld; men heeft n.l. in de bovenstaande afleiding voor 5 slechts 0 te substitueeren om geheel dezelfde uitkomst te verkrijgen. Beschouwen wij nu eens onderstaande tabel II, die de bewerkingen van tabel I, toegepast op de kostenfunctie $K=\frac{1}{2} \mathrm{P}^{2}+\mathrm{P}$. bevat.

Uit kolom (5) blijkt dat nu ook mijn waarde voor E steeds kleiner is dan 1 en dat dus ook in over het geheele verloop afnemende meeropbrengst vind.

Bij wijze van kantteekening merken wij op, dat de lezer die bekend is met de beginselen der analytische meetkunde verstandig doet met een en ander nog eens in teekening te brengen. Hierdoor wint het vraagstuk veel aan overzichtelijkheid en zoodoende worden resultaten verkregen, die overeenstemmen met de opmerkingen, die Edgeworth indertijd over deze questie gemaakt heeft.

Vervolgen wij nu het debat. De afwijking tusschen de beide definities ontstaat klaarblijkelijk als er overhead costs optreden. Dit is het critische punt, dat de Heer Roetink had behooren te vermelden en waarvan hij zich met de opmerking: „bewijs voor den lezer" heeft afgemaakt.

Op welke problemen slaat nu de theorie van de ,afnemende meeropbrengst"? $\mathrm{Z}_{\mathrm{ij}}$ onderzoekt de resultaten die de toevoeging van éên bepaald en als oneindig deelbaar verondersteld productiemiddel heeft op het eindproduct. De recente ana logieën met de natuurwetenschappen (wet van Guldberg en Waage e.d.) hebben dit zeer scherp doen uitkomen. In deze oorspronkelijke theorie spelen ook de prijzen geen rol. ${ }^{3}$ ). In dit geval (oneindig deelbare toevoegingen ontbreken van prijzen) kunnen dus geen overhead costs in de theorie worden betrokken. Immers, overhead costs zijn per sé niet oneindig deelbaar, ja zelfs tegenover een groote hoeveelheid product principieel ondeelbaar. Bovendien bestaan deze overhead costs zonder uitzondering of bijna zonder uitzondering uit elementen die ongelijksoortig zijn met het toegevoegde productiemiddel en is het dus om ze samen te brengen in een formule noodig den prijs in te lasschen ${ }^{4}$ ).

En ten slotte: de verdeeling van idle overhead over eenheden product is een vraagstuk, dat ten eenenmale niet mag worden geïdentificeerd met de vraagstukken van de onvolkomen verbindingen, die door de opbrengstwetten aan de orde worden gesteld.

Anders gezegd: als wij onderzoeken wat de resultaten van toevoeging van eenheden arbeid op een stuk grond zijn en wij komen te spreken over de vragen van afnemende of toenemende meeropbrengst, dan vergelijken wij de mutaties in de hoeveelheid arbeid alleen met de mutaties van de hoeveelheid product en niet de mutaties in hoeveelheid arbeid plus hoeveelheid grond (dit laatste is dan overhead cost) met de mutaties in de hoeveelheid product. In dit eerste geval geeft, zooals

3) Dit belet natuurlijk niet, dat men bij voortgezet onderzoek den invloed van de prijzen wel degelijk zal dienen te analyseeren.

1) M.a.w, indien in de formule $\mathrm{K}=\frac{1}{2} \mathrm{P}^{2}+\mathrm{P}+5$ de overhead costs 5 de kosten van den grond voorstelt aan welken grond arbeid is toegevoegd, dan heeft de onderhavige formule alleen zin als de eenheden arbeid en grond door omrekening tegen prijzen bij elkaar kunnen worden opgeteld. 
wij gezien hebben, de formule warmede ik het begrip afnenemende meeropbrengst definieer volkomen juiste resultaten.

Om onder toepassing van mijn formule $\mathrm{E}=\frac{\mathrm{K}}{\mathrm{P}}: \frac{\mathrm{dK}}{\mathrm{dP}}$ tot onjuiste resultaten te komen, moet de Heer Roetink de eenheden productiemiddelen in geld herleiden, en de overhead costs bij het veranderende kostenelement optellen en dus om de optelling mogelijk te maken - alle productie,middelen omrekenen in geld. In dit geval echter is de theorie van de opbrengstwetten (onderdeel van de leer van de organisatie) geheel verlaten en praten wij over een vraagstuk van den kostprijs! Dit niet te hebben vermeld en vermoedelijk ook niet te hebben gezien, mag den Heer Roetink zwaar worden aangerekend.

$E_{r}$ komen nu twee vragen naar voren:

1. Als het bezwaar tegen mijn definitie aldus teruggewezen kan worden, zijn er dan positieve argumenten, die ten gunste van deze definitie kunnen worden aangevoerd?

2. Hoe moet het geval, dat in een kostprijsformule $\left(\mathrm{K}=\frac{1}{2} \mathrm{P}_{2}+\mathrm{P}-5\right.$ inclusief 5 overhead costs en her leid in geld) dubbelzinnigheden kunnen ontstaan, worden behandeld?

Omtrent de eerste vraag merken wij het volgende op. Het voordeel, dat ik in deze definitie zie, is de groote uniformiteit die zij schept: dus een doelmatigheidsvoordeel, een zeer belangrijk criterium voor het beoordeelen van definities. Deze definitie geeft ons n.l. de mogelijkheid de elasticiteitscoëfficient ook op de opbrengstwetten toe te passen. Oorspronkelijk kennen wij het begrip elasticiteit van de vraag. Later ontstaat het begrip ,.elasticit- of supply" en nu wordt dit begrip en de adequate formules ook toepasbaar in de leer van de organisatie. Vooral wanneer men bedenkt dat deze theorie (opbrengstwetten) later in de theorie van den kostprijs worden toegepast, biedt deze uniformiteit zeer groote voordeelen. Dit is wat ik met de onderzoekingen in mijn oorspronkelijk artikel o.a. heb willen demonstreeren, ofschoon dit den Heer Roetink geheel schijnt te zijn ontgaan. Ik heb hiermede de geheele mathematische economische literatuur na Edgeworth vrijwel zonder uitzondering aan mijn zijde. Bijna alle schrijvers definieeren de opbrengstwetten met behulp van elasticiteitscoëffienten. En dit is ook zeer wel te begrijpen omdat hiernede de laatste groote fout, van de definitie Roetink die ik noemen wil, vermeden wordt. De definitie Roetink zondigt n.l. tegen een grondbeginsel van de mathematische voorstellingen en wel tegen het voorschrift, dat de gekozen voorstelling onafhankelijk van de gekozen eenheden moet zijn.

In de voorstelling Roetink beteekent de breuk $\frac{\Delta r_{n}}{\Delta K_{n}}$ de verhouding van de toename van de eenheden product tot de toename van de eenheden productiemiddelen. Drukt men b.v. het product uit in kilogrammen en het productiemiddel in liters en neemt het product toe met $\frac{1}{2} \mathrm{~kg}$ als men 1 liter productiemiddel toevoegt, dan is $\frac{\Delta r_{a}}{\Delta K_{n}}=\frac{1}{2}+\frac{1}{1}=\begin{aligned} & 1 \\ & 2\end{aligned}$ Behalve dat de breuk $\frac{\Delta r^{n}}{\Delta K_{n}}$ gebruikt wordt om door $\sum$ teekens te worden vergeleken met $\frac{\Delta r_{n+1}}{\Delta K_{n+1}}$ geeft zij tevens de helling van de kosten - c.q. opbrengst curve - in het onderzochte interval; in bovenstaand getallenvoorbeeld is de helling b.v. 1 op 2. Gaat men nu over op andere eenheden dan verandert de waarde van de breuk $\frac{\Delta r_{n}}{\Delta K_{n}}$ en dus ook de curve waar de breuk betrekking op heeft m.a.w. gevallen die op verschillende eenheden betrekking hebben zijn met behulp van de voorstelling niet vergelijkbaar.

Dit bezwaar vervalt bij de door mij gevoegde methode van het gebruik van de elasticiteitscoëfficient en deze verdient hiervoor als algemeene voorstellingswijze verre de voorkeur.

Ik heb hierop, in ander verband, in een paar vorige publicaties reeds gewezen ${ }^{5}$ ) en $i k$ wil bovendien nog vermelden, dat het laatste verschenen grote compilatiewerk over de wiskundige analyse in de economie van R. G. D. Allen „Mathematical analensis for economists" geheel de door mij voorgestane voorstelling gebruikt ${ }^{6}$ ) (een voorstelling die trouwens algemeen toegepast wordt) en de methode Roetink niet noemt.

Ten aanzien van de tweede vraag valt het volgende op te merken.

Tabel I toont ons, dat wij ten aanzien van de kostencurve drie begrippen moeten onderscheiden en wel de gemiddelde kosten (kolom (3) $\frac{\mathrm{K}}{\mathrm{P}}$ ), en grenskosten (kolom (4) $\frac{\mathrm{dK}}{\mathrm{dP}}$ ) en de elasticiteitscoëfficient van de kostencurve (kolom (5) n.l. $\frac{\text { gemiddelde kosten }}{\text { grenskosten }}=\mathrm{E}=\frac{\mathrm{K}}{\mathrm{P}}: \frac{\mathrm{dK}}{\mathrm{dP}}$

Het begrip meeropbrengst is hier niet alleen onvoldoende, maar tevens ontoelaatbaar. Past men het toch toe dan gaat men weer over tot het dooreenmengen van hoeveelheden en prijzen zooals de literatuur tot en met Marshall heeft gedaan en welke fout Edgeworth in de boven geciteerde artikelen ook maakt. Wij mogen dit den pioniers vergeven in erkentelijkheid voor het baanbrekende werk, dat zij hebben verricht; dat de Heer Roetink nu weer in deze fout vervalt en dit bovendien nog als een trouvaille beschouwt, bewijst alleen dat het noodzakelijk is de literatuur en de literatuurcritiek m.a.w. de dogma-geschiedenis) van een vak te kennen voor men er over gaat schrijven.

Ten slotte nog twee opmerkingen over dit punt teneinde verwarring te voorkomen. I $k$ heb steeds de formule $\mathrm{K}=1 / 2 \mathrm{P}^{2}+\mathrm{P}$ of $\mathrm{K}=1 / 2 \mathrm{P}^{2}+\mathrm{P}+5$ gebruikt. Klaarblijkelijk is dit een kostprijsformule. Consequent had ik bij kostprijsgevallen de formule $\mathrm{K}=1 / 2 \mathrm{P}^{2}+\mathrm{P}+5$ moeten gebruiken maar bij bespreking van gevallen van meeropbrengsten de formule $\mathrm{K}=1 / 2 \mathrm{P}_{2}+\mathrm{P}$ moeten gebruiken in den vorm $\mathrm{P}=V(2 \mathrm{~K}+1)-1$ waarin het product als functie van het kostenelement is uitgedrukt.

Dit zou de behandeling ongetwijfeld strenger maar voor lezers van dit maandblad zeker veel minder leesbaar hebben gemaakt en aan de resultaten zou niets zijn veranderd. Ook op eenige andere punten hebben wij wetenschappelijke strengheid opgeofferd aan de leesbaarheid.

De tweede opmerking is de volgende. Wij hebben geconcludeerd dat opbrengstvragen en kostprijsvragen niet mogen worden verward en dat bij het formuleeren van de wet van de afnemende meeropbrengst prijzen niet met hoeveelheden mogen worden verward. Dit beteekent dat men bij het formu leeren van de wet van de afnemende meeropbrengst geen prijzen mag gebruiken; in een later stadium, b.v. bij de toepassing van deze wet in vragen van kostprijs e.d. moeten deze prijzen natuurlijk in rekening worden gesteld. Hoe dit kan geschieden, is eveneens uit mijn oorspronkelijk artikel gebleken.

5) "Over het gebruik van de wiskunde in de economie" pag. 43 en "Eenige beschouwingen over het vraagstuk van de eenheden bij de quantitatieve analyse in de economie".

6) t.a.p. pag. 260. Cap. $10 \S 8$. 
Ten slotte kom ik tot een summiere behandeling van het derde punt. De Heer Roetink heeft voor de principieele vragen weiniq ruimte in beslag genomen (eigenlijk nog niet eens een geheele kolom) maar wel heeft hij ongeveer drie kolommen gevuld met onzakelijke emotionaliteiten. Waar ik de ruimte van mijn artikel beschikbaar heb gesteld om zelf te vertellen hetgeen de Heer Roetink voor de verediging van zijn standpunt ten onrechte niet heeft vermeld, reken ik mij ontslagen van de plicht om op de emotioneele kolommen nader in te gaan. Ik twijfel er niet aan dat de lezer deze kolommen ook op grond van mijn zakelijke uiteenzettingen naar hun juiste waarde zal weten te beoordeelen.

Amsterdam, April 1940.

\section{S. KLEEREKOPER}

\section{Slotwoord.}

Hieronder laat ik enkele zeer beknopt gehouden slotopmerkingen volgen.

1. „Thans" en de logica.

De Heer Dr Kleerekoper deelt mede, dat het van den aanvang af vast staat, dat men mag uitgaan van de wet der afnemende meeropbrengsten.

Deze bewering acht ik onjuist. Immers, in het M.A.B. van November 1938 heb ik eerst een (wel-is-waar korte) bespreking gegeven en daarna ben ik tot de conclusie gekomen:

Hieruit kan men dus concluderen, dat alleen de wet der afnemende meeropbrengsten geldt; en wel steeds voor elk technisch productiemiddel."

Bovendien blijkt hieruit, dat dit een conclusie is, gevonden zonder gebruik te maken van wiskundige vormen.

Op welke goede gronden men tot conclusies komt ten aanzien van het door mij aan de orde gestelde probleem, is voor dat probleem op zich zelf onverschillig.

In mijn toelichtingen in het M.A.B. van Maart 1940 zei ik reeds, dat met de door Dr $K$. gewrakte alinea een samenvatting van mijn geheel artikel is gegeven en dat in de daaraan voorafgaande alinea enige met behulp van wiskundige vormen gevonden conclusies zijn weergegeven.

Het is dus onjuist. indien men van de door niets gerechtvaardigde praemissie uitgaat, dat het slechts geoorloofd zou zijn, uitsluitend met behulp van wiskundige vormen gevonden conclusies in mijn samenvatting van het geheel te verwachten.

De door mij gegeven samenvatting bevat louter conclusies!

2. Verband met wiskunde.

Voorts dient te worden aangestipt, dat, waar de Heer Dr Kleerekoper boven spreekt van: ,dat wij op niet wiskundige gronden moeten uitgaan van de wet van de afnemende meeropbrengst", hij door deze manier van uitdrukken de lezers hier tegenstrijdigheden in de bewoordingen biedt. Immers, beide termen ,afnemende" en ,meeropbrengst" geven ondubbelzinnige wiskundige kwalificaties weer.

"Meeropbrengst" duidt erop, dat de rij der opbrengsten. in de rangschikking van de successievelijke toevoegingen, bestaat uit toenemende opbrengsten. Of anders gezegd: de rij der eerste verschillen van de rij der opbrengsten bestaat slechts uit positieve termen.

Afnemend" wil in dit verband zeggen, dat, in geval van telkens onderling gelijke toevoegingen, de rij der tweede verschillen slechts uit negatieve termen bestaat.

Een willekeurig getallenvoorbeeld moge dat toelichten. $\begin{array}{lllllll}100 & 150 & 190 & 221 & 244 & 260 & 270 \\ \text { (rij der opbrengsten) }\end{array}$
$\begin{array}{lllllll}50 & 40 & 31 & 23 & 16 & 10 & \text { (rij der ecrste verschillen) }\end{array}$ $\begin{array}{llllll}-10 & -9 & -8 & -7 & -6 & \text { (rij der tweede verschillen) }\end{array}$

De rij der opbrengsten vertoont dus in het gegeven gedeelte afnemende meeropbrengsten, in geval van steeds gelijkblijvende toevoegingen aan eenzelfde productiemiddel.
3. Definities ",afnemende meeropbrengsten".

a. In de eerste plaats wens ik aan te tonen (zie blz. 177 van genoemd Novembernummer), dat uit

$$
\Delta \bar{r}_{n}>\Delta \bar{r}_{n}+1 \ldots \ldots \ldots \ldots \ldots, \ldots \ldots\left(a^{\prime}\right)
$$

(bij steeds gelijke toevoegingen $\mathrm{k}=\Delta \mathrm{k}_{\mathrm{n}}$ voor elke $\mathrm{n}$; $\mathrm{n}=$ $\mathrm{O}$ en $\mathrm{n}$ positief geheel)

steeds voor toevoegingen van willekeurige grootte (practisch binnen een zeker eindig gebied) volgt:

$$
\Delta \mathrm{r}_{\mathrm{n}}>\frac{\Delta \mathrm{r}_{\mathrm{n}+1}}{\Delta \mathrm{k}_{\mathrm{n}}+1}
$$

- Op blz. 77 Nov. '38 is omgekeerd (a') afgeleid uit (a.). -

In het thans te bewijzen geval zij $\Delta k_{n}=k_{n+1}-k_{n}=$ p.k en $\Delta k_{n+1}=k_{n+2}-k_{n+1}=q \cdot k$, waarin $p$ en $q$ willekeurige positieve getallen zijn, groter dan 1 (waartoe men dus $\mathrm{k}$ klein genoeg kan kiezen). Indien de verhouding $\mathrm{p}: \mathrm{q}$ zelfs irrationaal is, dan is die irrationale verhouding steeds te vinden als de limiet van een rationaal getal en dat is steeds te herleiden tot de verhouding van twee gehele getallen. Dus men mag zonder bezwaar p en q bovendien geheel nemen.

$Z_{i j} k_{11}=\bar{k}_{j}$, dan is dus $k_{n+1}=\bar{k}_{j+p}$ en $k_{n+2}=\bar{k}_{j+p+q}$. Voorts is nu $r_{n}=\bar{r}_{j}, r_{n+1}=\bar{r}_{j+p}$ en $r_{n+2}=\bar{r}_{j+p+q}$.

(Op overeenkomstige wijze als voor $p$ en $q$ mag men zonder bezwaar voor $\mathbf{j}$ een zeker natuurlijk getal $\mathrm{n}$ nemen, terwijl voor $\mathrm{n}=\mathrm{O}$ tevens $\mathrm{j}==\mathrm{O}$.)

Nu volgt uit $\left(a^{\prime}\right)$ :

en dus ook:

$$
\Delta r_{n}>p \cdot \Delta \bar{r}_{j+p-1} \text { en } \Delta r_{n+1}<q \cdot \Delta r_{j+p-1}
$$

of ten slotte (a) (Q.E.D.).

De door mij gebezigde wiskundige uitdrukking voor de wet der afnemende meeropbrengsten is dus éénéenduidig in overeenstemming met de letterlijke betekenis dier termen. (De éénduidigheid bestaat in beide richtingen.)

Elke andere wiskundige formulering, die niet volkomen gelijkwaardig is met (a), deugt niet.

Of anders gezegd: alsdan gebruikt men de termen, ,afnemende meeropbrengsten" in een oneigenlijke betekenis. Men dient alsdan dus andere (goede) bewoordingen te gebruiken, bv. , afnemende productiviteit".

- Met (a) is bijv. wel gelijkwaardig

$$
\frac{\Delta r_{n}-1}{\Delta r_{n}}: \frac{\Delta k_{n}+1}{\Delta k_{n}}<i, ., \quad\left(a^{\prime \prime}\right)-
$$

De geboden wiskunde kan in verband met het reeds boven gegeven getallenvoorbeeld als volgt worden toegelicht.

Kent men $r_{1}=100, r_{2}=190$ en $r_{3}=270$, dan is $r_{1}=\bar{r}_{1}$, $r_{2}=\bar{r}_{3}$ en $r_{3}=\bar{r}_{\bar{r}}$. De rij der eerste verschillen is nu: $90 \ldots$ 80. Deze getallen moet men respectievelijk delen door 2 en 4 , wat resp. geeft 45 en 20 . Hieruit eerst volgt de gelding van de wet der afnemende meeropbrengsten. (Men kon hier volstaan met 80 te delen door 2 , enz.). ( $k=1$ is gemakshalve aangenomen.)

$b$. In de tweede plaats wens ik aan te tonen, dat een definitie van de wet der afnemende meeropbrengsten

$$
\mathrm{E}_{\mathrm{n}}=\frac{\mathrm{k}_{\mathrm{n}}}{\mathrm{r}_{\mathrm{n}}} \cdot \frac{\Delta \mathrm{r}_{\mathrm{n}}}{\Delta \mathrm{k}_{\mathrm{n}}}<1
$$

niet gelijkwaardig is met de als juist gebleken definitie (a).

Om dat aan te tonen is het voldoende om te laten zien, dat de definitie met $E_{n}$ in strijd kan komen met (a) dan wel met $\left(a^{\prime}\right)$. 
$\mathrm{Z}_{\mathrm{ij}} \overline{\mathrm{r}}_{10}=80, \overline{\mathrm{r}}_{13}=91$ en $\overline{\mathrm{r}}_{16}=108$, dan heeft men in de letterlijke zin der woorden te maken met toenemende meeropbrengsten en afnemende productiviteit van het productiemiddel. De meeropbrengsten zijn resp. 11 en 17 en de productiviteit van het productiemiddel is achtereenvolgens 8,7 en $63 / 4$ (maal $\frac{1}{k}$ ).

Voor $\mathrm{E}_{n}$ vindt men dan resp.

$$
\mathrm{E}_{10}=\frac{11}{24}<1 \text { en } \mathrm{E}_{13}=\frac{17}{21}<\mathrm{I} \text {. }
$$

Dus ondanks toenemende meeropbrengsten toch $\mathrm{E}_{\mathrm{n}}<1$.

Hiermede is reeds genoegzaam aangetoond, dat genoemde definitie met $E_{\|}$een onvoldoend criterium stelt.

c. In de derde plaats wens ik aan te tonen, dat een eventuele definitie van de wet der afnemende meeropbrengsten

$$
E^{\prime}{ }_{n}=\frac{K+k_{n}}{r_{n}} \cdot \frac{\Delta r_{n}}{\Delta k_{n}}<1
$$

evenmin gelijkwaardig is met (a) of met ( $\left.a^{\prime}\right)$.

- Zoals de lezer zich zal herinneren, betekent $K$ de som van de productiemiddelen, die in het beschouwde samenstel onveranderd blijven. -

$\mathrm{Z}_{\mathrm{ij}} \overline{\mathrm{r}}_{3}=80, \overline{\mathrm{r}}_{6}=91, \overline{\mathrm{r}_{\mathrm{j}}}=108$ en $\mathrm{K}=7 . \mathrm{k}\left(\mathrm{k}_{\mathrm{n}}=\mathrm{n} . \mathrm{k}\right)$, dan vindt men $\mathrm{E}_{3}=\frac{11}{24}<1$ en $\mathrm{E}^{\prime}{ }_{6}=\frac{17}{21}<1$, niettegenstaande de toeneming van de meeropbrengst.

Hiermede is reeds genoegzaam aangetoond, dat evenbedoelde definitie met $E_{n}^{\prime}$ eveneens een onvoldoend criterium geeft.

- Dat de, definities onder $b$ en $c$ niet gelijkwaardig zijn, is evident. -

d. Onder $b$ en $c$ had ik de getallen ook zo kunnen kiezen, dat men te maken had met afnemende meeropbrengsten en toch $\mathrm{E}_{n}>1, \mathrm{E}_{n}^{\prime}>1$.

Voorbeeld. $\mathrm{r}_{50}=45, \mathrm{r}_{51}=47, \mathrm{r}_{52}-48$ en $\mathrm{K}=50 . \mathrm{k}$; alsdan zijn $\mathrm{E}_{50}=22 / 9, \mathrm{E}_{\overline{5} 1}=1{ }^{4 / 47}, \mathrm{E}_{50}^{\prime}=4^{4 / 9}$ en $\mathrm{E}_{51}^{\prime}=$ $27 / 47$. - Ook is mogelijk $\mathrm{E}_{\mathrm{n}}<1$ en $\mathrm{E}_{n 1}^{\prime}>1$. -

e. Zijn slechts minimale toevoegingen van eindige grootte mogelijk, dan zijn de getallen $p$. q en j steeds geheel te kiezen (zie onder a). Zowel voor dit geval als voor het geval, dat men de toevoegingen op continue wijze zo klein kan kiezen als men zelf wenst, geldt de door mij geformuleerde definitie.

Deze blijft vanzelfsprekend eveneens gelden, indien $r$ een continue functie of zelfs een differentieerbare functie van $\mathrm{k}$ is, maar niets van dat alles wordt door mij vooropgezet. Nog minder ga ik op deze plaats daar verder op in, aangezien ik mij slechts behoef te houden aan de zeer geringe dosis elementair wiskundige kennis, welke $i k$ bekend heb verondersteld. Hierop behoef ik geen inbreuk te maken. - Daarentegen brengt de Heer Dr. Kleerekoper eerst in zijn bovenstaand artikel de differentieerbaarheid ter sprake, jazelfs stelt hij daarin de differentiëerbaarheid voorop. Een dergelijke handelwijze is onlogisch en tevens is de toepasselijkheid van zijn criterium daardoor zeer beperkt.

f. Kortheidshalve verwijs ik naar blz. 177 (2de kolom) van neerbedoeld Novembernummer. In verband met het bovenstaande blijkt dus, dat de Heer Dr. Kleerekoper in zijn Bedrijfseconomie, bij zijn getallenvoorbeelden, er niet één, maar twee begrippen ,,afnemende meeropbrengst" op nahield, die niet gelijkwaardig zijn. (Zie boven onder $b$ en $c$ ). Maar in zijn van blz, 35 geciteerde bewoordingen sluit hij aan bij het juiste begrip. (Zie boven onder a). Dus bij Dr. K. in totaal drie verschillende, ongelijkwaardige formuleringen voor , afnemende meeropbrengst".

m a b blz. 216
4. Gevolgeigenschappen.

$$
\text { a. Uit } \frac{\Delta r_{n}}{\Delta k_{n}}>\frac{\Delta r_{n}+1}{\Delta k_{n}+1}
$$

(voor elke $\mathrm{n} ; \mathrm{n}=0$ of positief geheel) volgt:

$$
\frac{r_{n}}{k_{n}}>\frac{\Delta r_{n}}{\Delta k_{n}}
$$

(voor elke $\mathrm{n}$ positief geheel).

Men kan even goed zeggen: Uit (a) volgt:

$$
E_{n}=\frac{k_{n}}{r_{n}} \cdot \frac{\Delta r_{n}}{\Delta k_{n}}<1
$$

(voor elke natuurlijke $\mathrm{n}$ ).

Het bewijs van deze gevolgeigenschap kan als volgt luiden $r_{s}=\Delta r_{0}+\Delta r_{1}+\ldots \ldots \ldots .+\Delta r_{n-1} ; r_{1} \equiv \triangle r_{0}$. $\mathrm{k}_{\mathrm{n}}=\Delta \mathrm{k}_{0}+\Delta \mathrm{k}_{1}+\ldots \ldots \ldots . .+\Delta \mathrm{k}_{\mathrm{n}-1} ; \mathrm{k}_{1} \equiv \Delta \mathrm{k}_{0}$.

$$
\frac{\Delta \mathrm{r}_{0}}{\Delta \mathrm{k}_{0}}>\frac{\Delta \mathrm{r}_{1}}{\Delta \mathrm{k}_{1}}>\ldots . . . \frac{\Delta \mathrm{r}_{\mathrm{n}}-1}{\Delta \mathrm{k}_{\mathrm{n}-1}}>\frac{\Delta \mathrm{r}_{\mathrm{n}}}{\Delta \mathrm{k}_{\mathrm{n}}} .
$$

Hieruit volgt in de eerste plaats

$$
\begin{aligned}
& \quad \frac{\mathrm{r}_{1}}{\mathrm{k}_{\mathrm{l}}}>\frac{\Delta \mathrm{r}_{\mathrm{i}}}{\Delta \mathrm{k}_{\mathrm{i}}} \text { en vervolgens } \\
& \frac{\Delta \mathrm{r}_{\mathrm{j}}+\Delta \mathrm{r}_{\mathrm{j}+1}}{\Delta \mathrm{k}_{\mathrm{j}}+\Delta \mathrm{k}_{\mathrm{j}+1}}>\frac{\Delta \mathrm{r}_{\mathrm{j}}+1}{\Delta \mathrm{k}_{\mathrm{j}+1}}>\frac{\Delta \mathrm{r}_{\mathrm{j}}+2}{\Delta \mathrm{k}_{\mathrm{j}}+2}
\end{aligned}
$$

$(\mathrm{j}=\mathrm{O}, 1, \ldots \ldots \ldots, \mathrm{n}-2)$.

Want $\Delta \mathbf{k}_{\mathbf{j}+1} \cdot\left(\Delta \mathbf{r}_{j}+\Delta \mathbf{r}_{\mathbf{j}+1}\right)>\Delta \mathbf{r}_{\mathrm{j}+1} \cdot\left(\Delta \mathrm{k}_{\mathrm{j}}+\Delta \mathrm{k}_{\mathrm{j}+1}\right)$, daar $\Delta \mathrm{k}_{\mathrm{j}+1} \cdot \Delta \mathrm{r}_{\mathrm{l}}>\Delta \mathrm{r}_{\mathrm{j}+1} \cdot \Delta \mathrm{k}_{\mathrm{l}}$. immers $\frac{\Delta r_{j}}{\Delta k_{j}}>\frac{\Delta r_{j}+1}{\Delta k_{j}+1}$.

In het biezonder voor $\mathfrak{j}=0$ geldt:

$$
\frac{\Delta \mathrm{r}_{0}+\Delta \mathrm{r}_{1}}{\Delta \mathrm{k}_{0}+\Delta \mathrm{k}_{1}}=\frac{\mathrm{r}_{2}}{\mathrm{k}_{2}}>\frac{\Delta \mathrm{r}_{1}}{\Delta \mathrm{k}_{1}}>\frac{\Delta \mathrm{r}_{2}}{\Delta \mathrm{k}_{2}} \text {. }
$$

De te bewijzen stelling is dus reeds bewezen voor $\mathrm{n}=1$ en $\mathrm{n}=2$.

Stel, dat de stelling reeds is bewezen voor zekere index $n$, dan zullen we nu bewijzen, dat ze dan tevens geldt voor de index $\mathrm{n}+1$.

We krijgen nu achtereenvolgens: $\frac{r_{n}}{k_{n}}>\frac{\Delta r_{n}}{\Delta k_{n}}$ of $\Delta k_{n} \cdot r_{n}>\Delta r_{n} \cdot k_{n}$ of $\Delta k_{n} \cdot\left(r_{n}+\Delta r_{n}\right)>\Delta r_{n} \cdot\left(k_{n}+\Delta k_{n}\right)$ of $\Delta k_{n} \cdot r_{n+1}>\Delta r_{n} \cdot k_{n+1}$ of $\frac{r_{n}+1}{k_{n+1}}>\frac{\Delta r_{n}}{\Delta k_{n}}$ dus stellig $\frac{r_{n}+1}{k_{n}+1}>\frac{\Delta r_{n}+1}{\Delta k_{n}+1}$

Daar de stelling bewezen is voor $\mathrm{n}=2$, geldt ze dus ook voor $\mathrm{n}=3$, maar nu ook voor $\mathrm{n}=4$, enz., derhalve is de stelling bewezen voor iedere natuurlijke $\mathrm{n}$ (en wel door toepassing van het principe van volledige inductie).

b. Onmiddellijk uit het voorgaande volgt, dat uit (a) eveneens volgt:

$$
\frac{r_{n}+1}{k_{n}+1}>\frac{\Delta r_{n}}{\Delta k_{n}}
$$

(voor elke natuurlijke $\mathrm{n}$; voor $\mathrm{n}=0$ geldt in (c) het gelijkieken).

Men kan even goed zeggen: Uit (a) volgt:

$$
\mathrm{E}_{\mathrm{n}+1}=\frac{\mathrm{k}_{\mathrm{n}}+1}{\mathrm{r}_{\mathrm{n}+1}}, \frac{\Delta \mathrm{r}_{\mathrm{n}}}{\Delta \mathrm{k}_{\mathrm{n}}}<\mathrm{i} \cdot . \cdot
$$

(voor elke natuurlijke $\mathrm{n}$ ).

In verband met (a) ziet men onmiddellijk in, dat $\mathrm{E}_{\mathrm{n}}<\mathrm{E}_{\mathrm{n}}$.

c. Daar de Heer Dr. Kleerekoper gebruik maakt van de uitdrukking $\mathrm{E}=\frac{\mathrm{K}}{\overline{\mathrm{P}}}: \frac{\mathrm{dK}}{\mathrm{d} \mathrm{P}}<1$, merk ik volledigheidshalve het volgende op. 
In de door mij gebruikte notatie krijgt men daarvoor de uitdrukking:

$$
\underline{\mathrm{E}}_{\mathrm{n}} \equiv \frac{\mathrm{k}_{\mathrm{n}}}{\mathrm{r}_{\mathrm{n}}} \cdot \frac{\mathrm{dr}_{\mathrm{n}}}{\mathrm{dk}_{\mathrm{n}}}<1
$$

indien dus r een differentiëerbare functie van $k$ is. Daar Dr. K. ten slotte blijkbaar besluit tot een begrip voor $E$, overeenkomende met $E_{n}$ en $E_{n}$, kan ik met evengenoemde uitdrukking volstaan. - Voor de dubbelzinnigheid van Dr. K.'s definitie van $\mathrm{E}$, zie $5 c$. -

Daar in mijn uiteenzettingen de grootheden, voorzien van het teken $\triangle$, alle steeds positief zijn, laat ik in de toestand, aangeduid door de index $n, \triangle k_{n}>0$ op zodanige wijze tot nul naderen, dat de toestand $n+1$ nadert tot toestand $n$, en $\Delta k_{n-1}>0$ op zodanige manier tot nul naderen, dat de toestand $n-1$ nadert tot toestand $n$. In toestand $n$ vind $i k$ zodoende de rechterafgeleide en de linkerafgeleide, die hier gelijk zijn, zodat met recht kan worden gesproken van de afgeleide, behorende bij toestand $\mathrm{n}$.

Men ziet na het voorafgaande nu onmiddelijk in, dat in het onderhavige geval bij voortduring geldt

$$
\mathrm{E}_{\mathrm{n}}>\mathrm{E}_{\mathrm{n}}>\overline{\mathrm{E}}_{\mathrm{n}} \text {. }
$$

Boven onder $3 b$ hebben we aangetoond de onhoudbaarheid van de definitie van de wet der afnemende meeropbrengsten met behulp van de ongelijkheid $E_{n}<1$.

Op overeenkomstige wijze kan men de onhoudbaarheid van de definitie van bedoelde wet aantonen, indien gedefiniëerd met $E_{n}<1$, eventueel door toepassing van de onder $4 \mathrm{~b}$ gevonden eigenschap $E_{n}<E_{n}$.

Derhalve is de definitie met $\mathrm{E}_{11}<1$ evenzeer onhoudbaar, in verband met de eigenschap $E_{n}<E_{n}<E_{n}$. (Ze vertegenwoordigen alle drie eenzelfde grondbegrip.)

De eigenschappen $\left(c^{\prime}\right),\left(d^{\prime}\right)$ en $\left(e^{\prime}\right)$ volgen uit $(a)$, maar omgekeerd volgt $(a)$ niet uit $\left(c^{\prime}\right),\left(d^{\prime}\right)$ of $\left(e^{\prime}\right)$.

Derhalve: De Heer Dr. Kleerekoper gebruikt als definiëerende eigenschap een gevolgeigenschap van de juiste definieerende eigenschap, welke gevolgeigenschap niet gelijkwaardig is met de juiste definiërende eigenschap.

\section{Verschillende rectificaties.}

Zonder volledig te willen zijn, vestig ik de aandacht van de lezers nog op de volgende punten.

a. De Heer Dr. Kleerekoper zegt boven ergens:

..Dit is wat de Heer Roetink bedoelt, als hij zegt, dat mijn definitie van afnemende meeropbrengst ook nog toenemende meeropbrengst toelaat."

Dit naar aanleiding van zijn eerste tabel, als hij ook $\mathrm{E}>1$ vindt.

Het is juist omgekeerd: indien $\mathrm{E}>1$, dan spreekt Dr, K. per zijn definitie reeds van toenemende meeropbrengsten. Maar dan is er slechts sprake van toenemende productiviteit en dat is een onvoldoend criterium om reeds te kunnen spreken van toenemende meeropbrengsten in de eigenlijke zin der woorden.

b. Dat de Heer Dr. Kleerekoper in zijn tweede tabel voor $E$ steeds waarden vindt, die kleiner zijn dan 1, komt slechts door het biezonder gekozen voorbeeld, waaraan hij zonder enige rechtvaardiging een algemene conclusie verbindt, als zou door hem zijn aangetoond, dat zijn definitie houdbaar is.

Tegen deze manier van doen bestaat principiëel bezwaar en op deze wijze wordt niets bewezen of aannemelijk gemaakt! Bovendien is zijn conclusie, houdbaarheid van zijn definitie, boven grondig weerlegd.
$Z_{i j n}$ tabelen laten wel zien, dat mijn criterium voor af nemende meeropbrengsten juiste resultaten oplevert en bijvoorbeeld onaihankelijk van overhead costs is.

c. Een principiëel bezwaar tegen Dr. K.'s definitie van $E$ is, dat zij dubbelzinnig is, Uit zijn definitie blijkt niet, of hij met $K$ bedoelt $k_{n}$ dan wel $K+k_{n}$, dus of hij met $E$ bedoelt $E_{n}$ dan wel $E_{n}^{\prime}$, zoals ik dat boven onder $3 b$ en $3 c$ heb aangegeven.

Daarenboven moet ernstig principiëel bezwaar worden gemaakt tegen $\mathrm{Dr}$. K.'s gebruik van $\mathrm{E}$ ten aanzien van zijn twee tabellen. Immers, in de eerste tabel bedoeld hij $E_{n}^{\prime}$ en in de tweede tabel $E_{n}$. Dus hij gebruikt in eenzelfde betoog eenzelfde symbool $E$ ) voor twee verschillende begrippen ( $E_{n}^{\prime}$ en $E_{n 1}$ ). - De limietovergang heeft op de begrippen zelf geen invloed. -

d. Het verwijt van den Heer Dr. K., als zou ik de problemen van ,opbrengstwetten" en ,kostprijs" met elkaar heb ben verward, moet ik onvoorwaardelijk en met de meeste beslistheid terugwijzen; kortheidshalve verwijs ik naar 3 .

In mijn artikel van November 1938 heb ik duidelijk het verband tussen de wet der afnemende meeropbrengsten en de kosten aangegeven. Maar niet met de kostprijs, want ik had mij bij voorbaat een beperking opgelegd, omdat het mij te doen was om de grondbegrippen en om een logische opbouw. Bedoelde beperking hield in, dat ik de prijzen niet in mijn beschouwingen heb betrokken. Wie dat niet respecteert, doet dientengevolge onrechtvaardige verwijten, die niet ter zake dienende zijn. Van een dooreenmengen van hoeveelheden en prijzen is bij mij geen sprake!

\section{e. De bewering van Dr. K.}

,Om onder toepassing van mijn (d.w.z. Dr. K.'s) formule $\mathrm{E}=\frac{\mathrm{K}}{\mathrm{P}}: \frac{\mathrm{dK}}{\mathrm{dP}}$ tot onjuiste resultaten te komen, moet de Heer Roetink de eenheden productiemiddelen in geld herleiden, de overhead costs bij het veranderende kostenelement optellen en dus - om de optelling mogelijk te maken - alle productiemiddelen omrekenen in geld",

berust eveneens op onjuiste inzichten.

Kortheidshalve verwijs $i k$ in dit verband naar $4 c, 5 c, 5 d$ en M.A.B. van November 1938, blz. 178, eerste kolom midden en verder.

Voorts dient te worden opgemerkt, dat hetgeen $D_{r}$. K. een formule noemt, slechts een identiteit is, een definitie van $E$; $E$ is een verkorte schrijfwijze voor het rechterlid van bedoelde identiteit.

Het gaat uiteindelijk niet om de definitie van $E$, maar om de definitie van de wet der afnemende meeropbrengsten met behulp van E; nl. of die wet gedefiniëerd kan worden door de ongelijkheid $\mathrm{E}<1$.

Boven is bewezen, dat dit criterium (ongeacht genoemde dubbelzinnigheid) onvoldoende en onhoudbaat is en bovendien, dat het slechts een gevolgeigenschap is van de juiste definitie, indien ze gebruikt wordt in de betekenis van $\mathrm{E}_{\mathrm{n}}$. definitie, indien $\mathrm{E}$ gebruikt wordt in de betekenis van $\mathrm{E}_{\mathrm{n}}$.

$$
\text { J. H, ROETINK J.Hzn. }
$$

(Discussie gesloten, REDACTIE).

\section{BOEKBESPREKING}

De Winstbelasting, door Prof. Dr. P. J. A. Adriani.

Dit werkje is de verzameling van eene reeks artikelen, verschenen in het Weekblad voor Privaatrecht, Notaris-ambt en Registratie. De voornaamste artikelen van het Besluit op de Winstbelasting 1940 worden er in behandeld. Het gedeelte onder III "De Winstberekening” is zeer belangrijk. Uitvoerig 